\title{
Length of stay of COPD hospital admissions between 2006 and 20 I0: a retrospective longitudinal study
}

This article was published in the following Dove Press journal:

International Journal of COPD

18 March 2015

Number of times this article has been viewed

\author{
Timothy H Harries' \\ Hannah V Thornton ${ }^{2}$ \\ Siobhan Crichton' \\ Peter Schofield' \\ Alexander Gilkes' \\ Patrick T White' \\ 'King's College London, King's Health \\ Partners, Division of Health and \\ Social Care Research, London, UK; \\ ${ }^{2}$ University of Bristol, Centre for \\ Academic Primary Care, NIHR School \\ for Primary Care Research, School \\ of Social and Community Medicine, \\ Canynge Hall, Bristol, UK
}

Background: Hospitalizations for COPD are associated with poor patient prognosis. Length of stay (LOS) of COPD admissions in a large urban area and patient and hospital factors associated with it are described.

Methods: Retrospective longitudinal study. All COPD patients registered with London general practitioners and admitted as an emergency with COPD (2006-2010), not having been admitted with COPD in the preceding 12 months were included. Association of patient and hospital characteristics with mean LOS of COPD admissions was assessed. Association between hospital and LOS was determined by negative binomial regression.

Results: The total number of admissions was 38,504, from 22,462 patients. The mean LOS for first admissions fell by 0.8 days (95\% confidence interval [CI]: $0.7-1.5$ ) from 8.2 to 7.0 days between 2006 and 2010. Seventy-nine percent of first admissions were $\leq 10$ days, with a mean LOS of 3.7 days (2009-2010). The mean LOS of successive COPD admissions of the same patients was the same or less throughout the study period. The interval between successive admissions fell from a mean of 357 days between the first and second admission to a mean of 19 days after eight admissions. Age accounted for $2.3 \%$ of the variance in LOS. Socioeconomic deprivation did not predict LOS. Fewer discharges happened at the weekend (1,893/day) than on weekdays (5,218/day). The mean LOS varied between hospitals, from 4.9 days $(95 \%$ CI: 3.8-5.9) to 9.5 days (95\% CI: 8.6-10.3) when adjusting for clustering, age, sex, and socioeconomic deprivation.

Conclusion: The fall in LOS of the first COPD admission between 2006 and 2010 reflects international trends. The stability of LOS in successive admissions suggests that increasing severity of disease does not affect recovery time from an exacerbation. Variations between hospitals of nearly 5 days in LOS for COPD admissions suggests that significant improvements in patient outcomes and in savings in health care utilization could be made in hospitals with longer LOS.

Keywords: general practice, hospitalization, LOS

\section{Background}

COPD is a leading cause of emergency hospital medical admissions worldwide and the second largest cause within the UK. ${ }^{1,2}$ Hospital admissions account for over $60 \%$ of the direct cost of the management of COPD. ${ }^{3,4}$ Frequent exacerbation-related admissions are associated with worsening lung function, poorer quality of life, increased risk of subsequent exacerbation, and a decline in health status, especially following a second severe exacerbation. ${ }^{5-7}$ Hospital admission is independently associated with all-cause mortality among COPD patients. $^{8}$ Suissa et al have suggested that delaying the occurrence of a patient's second severe COPD exacerbation and intensifying
Correspondence: Timothy $\mathrm{H}$ Harries King's College London, King's Health Partners, Division of Health and Socia Care Research, 9th Floor Capital House, Weston Street, London, UK Tel +44207848 8679

Email timothy.harries@kcl.ac.uk 
inpatient treatment could be strategic management targets in preventing early mortality in COPD. ${ }^{7}$ Few studies have examined the effect of repeated admissions on the length of hospital stay (LOS) in COPD. In Australia, a positive association was found between LOS and the number of COPD admissions, but the comparison was based on fewer than 100 patients. ${ }^{9}$ Variation in LOS among frequently admitted patients might suggest that some patients would benefit from more intensive treatment.

The drive to reduce long hospital stays for COPD patients has made LOS a marker of quality in COPD management in secondary care. ${ }^{10}$ Possible influences on the LOS of COPD admissions include age, socioeconomic deprivation, comorbidities, ${ }^{11,12}$ disease severity, ${ }^{13}$ and hyperglycemia. ${ }^{14,15}$ Health care provider factors that have predicted LOS include the provision of social care within the community, ${ }^{16}$ the day of the week of hospital admission, ${ }^{17}$ and the configuration of hospital units. ${ }^{18}$ Audits of hospital care have identified variation in the quality of care provided to COPD patients and have linked this to variation in LOS. ${ }^{18-22}$ No studies have compared comprehensive, long-term data on LOS between hospitals. Addressing variation in LOS between hospitals may provide an opportunity for hospital managers and those commissioning services to improve the quality of care for COPD patients.

This study aimed to describe LOS of all COPD hospital admissions of patients registered with general practices in London over a 4-year period and to determine the variation in LOS of COPD admissions between hospitals.

\section{Methods}

\section{Study setting}

London, the setting of this study, has an ethnically and socioeconomically diverse population of approximately 7.5 million people. ${ }^{23}$

\section{Study design and data source}

This was a retrospective longitudinal observational study of all COPD patients registered at London general practices who had emergency COPD hospital admissions between April 1, 2006 and March 31, 2010. The England National Health Service (NHS) Information Centre ${ }^{24}$ provided routinely collected data from the Hospital Episodes Statistics (HES) dataset, an inclusive record of NHS hospital activity within England. ${ }^{24,25} \mathrm{HES}$ tracks every hospital admission in the NHS, providing publicly accessible data. Each HES record contains anonymized (but uniquely identified) information relating to an emergency hospital admission, including patient demographics, Index of Multiple Deprivation (IMD) score of the patient's address and registered general practitioner, diagnostic and procedural codes, admitting hospital, admission and discharge dates, discharge destination, and LOS. IMD is a multidimensional score based on decennial national census data and annual local authority population data reflecting socioeconomic deprivation within a geographical area based on the residential address of the patient. ${ }^{26}$ The diagnosis field was set to identify all patient admissions with a primary diagnosis for that admission of COPD (International Classification of Diseases [ICD]-10 codes J40-J44) between 2005 and 2010.

\section{Patient and hospital inclusion criteria}

Analysis of LOS was principally carried out in patients whose first COPD admission during the study period had been preceded by a period of at least 12 months without a COPD admission, and who were aged $\geq 45$ years at the time of that current admission. ${ }^{27}$ For convenience, these are henceforth referred to as eligible patients. These criteria were applied to remove patients whose first admissions might have been influenced in their LOS by having followed previous admissions within a period of 12 months. For convenience, these are henceforth referred to as ineligible patients, although we have conducted some analysis on these patients too. Previous admissions were considered to be a significant factor in worsening disease ${ }^{7}$ and possibly in prolonging the LOS of subsequent admissions. The exclusion of younger patients was consistent with the criteria used in clinical trials of treatments for COPD. ${ }^{28-31}$ Younger patients may differ from the majority of older patients with COPD in their disease pathology and natural history. ${ }^{32}$

Hospital trusts were identified by their provider codes and were included in the analysis if they had a record of $\geq 100$ COPD patient admissions during the study period. This criterion was applied to allow a comparison of hospitals that held responsibility for emergency admissions whose medical care might have been expected to include COPD. Admissions to hospitals specializing in operative procedures for COPD including bronchial stenting, bullectomy, lung volume reduction, and transplantation were excluded. If two or more hospitals had merged during the study period to form a larger NHS trust, the admissions from each of the hospitals were combined. These mergers usually occurred between neighboring hospitals, meaning that patients within their catchment areas would have had a similar likelihood of being admitted to either hospital.

\section{Coding of length of stay}

The LOS of any patient admitted to hospital and discharged on the same day was coded in the HES database as 0 days. 
For this study, these admissions were recoded with a LOS of 0.5 days.

\section{Patient demographics}

Eligible patients, those not admitted for COPD within 12 months preceding their first admission in the study period, were compared to those (ineligible patients) who had been admitted for COPD within 12 months preceding their first admission in the study period, with respect to their age, sex, and socioeconomic deprivation scores. The differences between the groups were analyzed using the independent samples $t$-test.

\section{Analysis of all COPD admissions and first COPD admissions}

To examine the change in LOS throughout the study, the mean LOS of all COPD admissions among patients aged $\geq 45$ years, including patients who had been admitted for COPD within 12 months preceding the first admission, was calculated for each year from 2006 to 2010. The mean LOS of all first COPD admissions in the study period, in those patients with no COPD admissions in the 12 months preceding their first admission, was calculated for each year from 2006 to 2010 . The independent samples $t$-test was used to compare the change in the mean LOS of all COPD admissions between 2006 and 2010 and to compare the change in the mean LOS of first admissions between 2006 and 2010.

To assess the effect of repeat admissions on the mean LOS, we calculated the mean LOS of first and all subsequent admissions of those patients whose first admission was in 2006/2007. The time between the date of the first admission and the date of each subsequent admission was determined.

To determine the influence of patient characteristics on LOS among the eligible patients, two-tailed partial correlations were sought between mean patient age and mean patient IMD score per admission and mean LOS per admission. First admissions and readmissions were included.

\section{Analysis of COPD admissions by hospital}

To examine the influence of the hospital on the LOS, the mean LOS of all COPD admissions among eligible patients was compared between the 29 included hospitals, following adjustment for patient age, sex, and IMD score, and the effect of clustering of patients within hospitals. Negative binomial regression was used to allow for overdispersion of data, with each hospital entered as a separate term in the linear model as well as the above confounders. The hospital names were concealed in the results. The same analysis was repeated comparing LOS between hospitals for COPD admissions of $\leq 10$ days and for COPD admissions of $\leq 10$ days with deaths excluded. Ten days was chosen as the threshold LOS for this element of the analysis because while the proportion of patients admitted for more than 10 days was small, they had a disproportionate influence on the overall mean LOS due to the protracted LOS of many of them. For this reason, we have presented the distribution of hospital mean LOS for stays of $\leq 10$ days as the primary outcome.

\section{Analysis of weekend variation in admissions and discharges}

To determine the influence of weekend admission on LOS among admissions of $\leq 10$ days, the number of discharges on weekend days was compared to the number on weekdays, expressed as discharges per day. The mean LOS of weekend and weekday admissions was calculated using an independent samples $t$-test. The likelihood of same-day discharge was compared between weekend and weekday using an odds ratio (OR) test.

The statistical package SPSS (v20; IBM Corporation, Armonk, NY, USA) was used for data analysis. Ethics approval was not required for this study, which used routinely collected anonymized data to inform delivery of care.

\section{Results}

COPD admissions $(51,305)$ from 26,007 patients aged $\geq 45$ years registered with general practices in London were recorded between April 1, 2006 and March 31, 2010; 22,462 of these admitted patients had not been admitted to hospital with an exacerbation of COPD during the 12 months before inclusion in the study (eligible patients); 38,504 COPD admissions, comprising multiple admissions of the 22,462 eligible patients, were included in the analysis.

Eligible patients $(22,462)$ and ineligible patients $(3,545)$ had similar age and sex distributions (Table 1). Ineligible patients were significantly more deprived than eligible patients, with a worse mean socioeconomic deprivation score of 2 (95\% confidence interval [CI]: 1.6-2.5) points on a scale from $0-88$. Six point three percent of the eligible patients died in hospital. The outcome of admission was not available for $2 \%$ of the patients.

\section{Group and individual variations in length of stay of COPD admissions}

Between 2006 and 2010, the mean LOS among first admissions of eligible patients aged $\geq 45$ years fell by 0.8 days (95\% CI: $0.7-1.5$ ) from 8.2 to 7.0 days. The mean LOS of 
Table I Comparison of eligible patients $(22,462)$ and ineligible patients (3,545), 2006-2010

\begin{tabular}{lll}
\hline Patient characteristic & $\begin{array}{l}\text { Mean } \\
\text { (SD) }\end{array}$ & $\begin{array}{l}\text { Difference between } \\
\text { means }( \pm 95 \% \mathrm{CI})\end{array}$ \\
\hline $\begin{array}{l}\text { Patient age (years) } \\
\quad \text { Eligible }\end{array}$ & $72.8(\mathrm{II} . \mathrm{I})$ & $0.1(-0.23$ to 0.55$)$ \\
$\quad \begin{array}{l}\text { Ineligible } \\
\text { Males (\%) }\end{array}$ & $72.7(10.2)$ & \\
$\quad$ Eligible & $51.7(0.5)$ & $0.9(-0.01$ to 0.03$)$ \\
$\quad$ Ineligible & $52.6(0.5)$ & \\
$\begin{array}{l}\text { Deprivation score (IMD) } \\
\quad \text { Eligible }\end{array}$ & $28.0(13.2)$ & $2.0(\mathrm{I} .58$ to 2.52$)$ \\
$\quad$ Ineligible & $30.0(13.2)$ & \\
\hline
\end{tabular}

Abbreviations: $\mathrm{Cl}$, confidence interval; IMD, Index of Multiple Deprivation; $\mathrm{SD}$, standard deviation.

all COPD admissions fell by 0.8 days (95\% CI: $0.5-1.1)$ from 8.0 to 7.2 days (Figure 1). There were no significant differences in mean LOS over the same period between all admissions and first admissions among those not admitted during the preceding 12 months.

There were 30,560 (79.4\%) admissions of $\leq 10$ days. Between 2006 and 2010, the mean LOS among admissions $\leq 10$ days fell by 0.24 days ( $95 \%$ CI: $0.15-0.34$ ) from 3.92 to 3.68 days. Correlation between patient age and LOS was weak $(r=0.15, P<0.0001)$. No correlation was found between IMD score and LOS.

During successive COPD hospital admissions, the mean LOS per admission remained stable (Figure 2). The mean

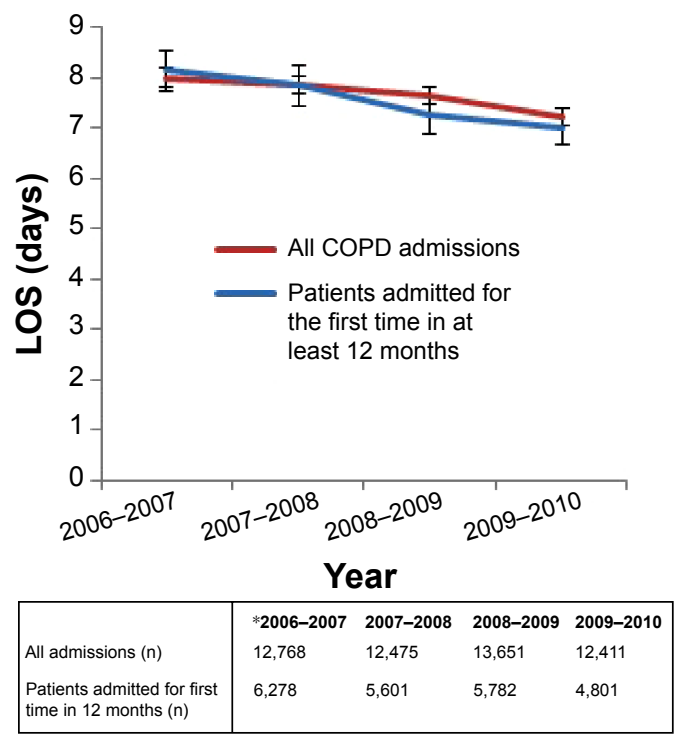

Figure I Mean LOS ( $\pm 95 \% \mathrm{Cl}$ ) of all COPD admissions (2006-2010) among patients aged $\geq 45$ years and mean LOS $( \pm 95 \% \mathrm{Cl})$ of patients aged $\geq 45$ years admitted for the first time in at least 12 months (2006-2010).

Note: *Period for each year ran from April I to March 31.

Abbreviations: $\mathrm{Cl}$, confidence interval; LOS, length of stay.
LOS at each time point was not influenced by deaths in the group. The interval between admissions decreased with each succeeding admission up to the ninth admission. Patients who died during these admissions had a longer mean LOS than survivors (13.3 days vs 7.5 days; mean difference of 5.8 days [95\% CI: $4.62-6.84])$.

\section{Hospital factors in length of stay for COPD admissions}

The distribution of the median (interquartile and full range) LOS of COPD admissions to 29 hospitals reporting more than 100 COPD admissions of patients registered with London general practices over the study period is shown in Figure 3. One specialist hospital was excluded.

The mean LOS varied between different hospitals from 4.9 days (95\% CI: $3.8-5.9)$ to 9.5 days (95\% CI: 8.6-10.3) when adjusting for clustering, age, sex, and geographical socioeconomic deprivation score (Figure 4). For those admissions of $\leq 10$ days, the mean LOS varied between hospitals from 2.9 days ( $95 \%$ CI: $2.4-3.5$ ) to 4.6 days ( $95 \%$ CI: $4.4-4.8$; Figure 5). Hospitals were ordered in Figures $4-6$ by ascending LOS of admissions $\leq 10$ days to remove the distorting effect on the ordering of the mean LOS of small numbers of admissions with very long LOS. There was no difference in the comparison of LOS between hospitals when adjustment was made for COPD admissions leading to death (Figure 6).

\section{Weekend variation in admissions and discharges}

Among admissions with a LOS of $\leq 10$ days, fewer discharges took place at the weekend (1,893 per day) than on weekdays $(5,218$ per day). Same-day discharge in these patients was also less likely at the weekend than on a weekday (9.9\% vs $15.3 \%$, OR: $0.61,95 \%$ CI: $0.52-0.70)$. The mean LOS for these patients was not statistically significantly different between those admitted at the weekend $(n=7,141$, mean $\operatorname{LOS}=3.94$ days) and those admitted during the week ( $\mathrm{n}=22,796$, mean $\operatorname{LOS}=3.90$ days, $t=0.965, P=0.334)$. There was no difference between hospitals in the proportion of COPD patients discharged at the weekend.

\section{Discussion \\ Main findings}

The LOS of admissions for COPD fell significantly over the 4 years of the study, in keeping with reported national and international trends. ${ }^{18,33}$ The LOS per admission did not increase with repeated COPD admissions but a narrowing 


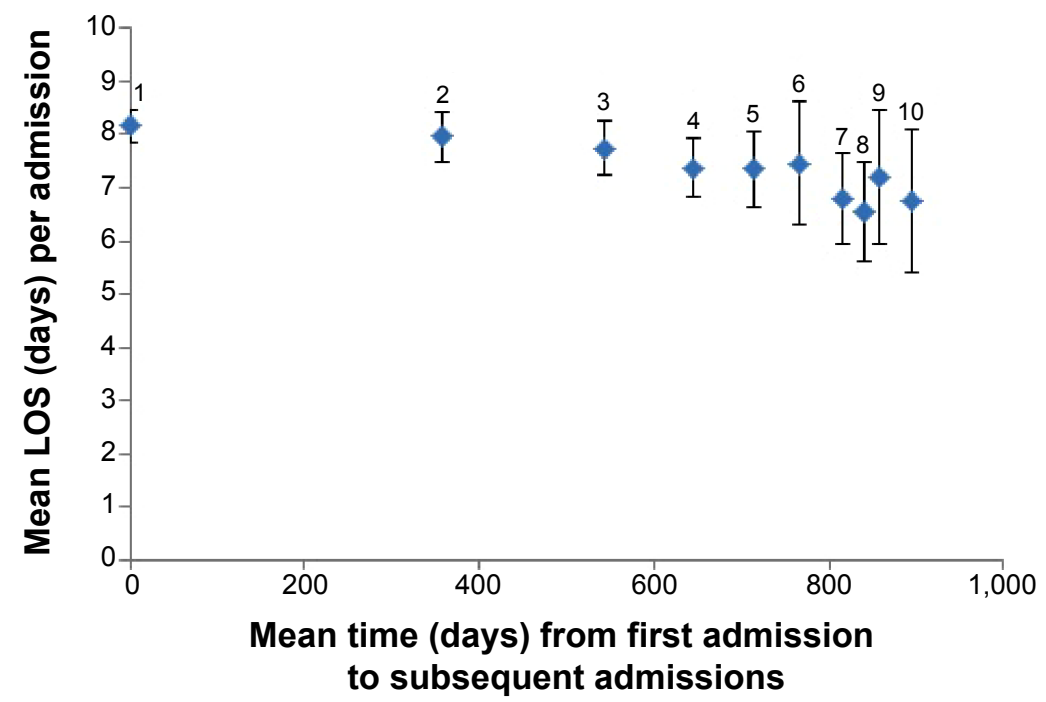

\begin{tabular}{|lllllllllll|}
\hline Admission & 1 & 2 & 3 & 4 & 5 & 6 & 7 & 8 & 9 & 10 \\
Patients (n) & 6,278 & 2,773 & 1,551 & 982 & 665 & 452 & 321 & 241 & 185 & 142 \\
\hline
\end{tabular}

Figure 2 Mean LOS per COPD admission $( \pm 95 \% \mathrm{Cl})$ among study patients not admitted for COPD during the preceding 12 months, plotted against mean time in days to that admission from their first admission in 2006-2007.

Abbreviations: $\mathrm{Cl}$, confidence interval; LOS, length of stay.

of time between admissions was seen. Age was a weak predictor of LOS and patient geographical socioeconomic deprivation score (IMD) was not a predictor of LOS. There were significant differences between hospitals in their mean LOS by almost a factor of two when all admissions were taken into account. These differences were sustained when adjustment was made for admissions $>10$ days and for deaths during admission. In this study, there were significantly fewer discharges of COPD patients at weekends and we found no difference between hospitals in weekend discharges.

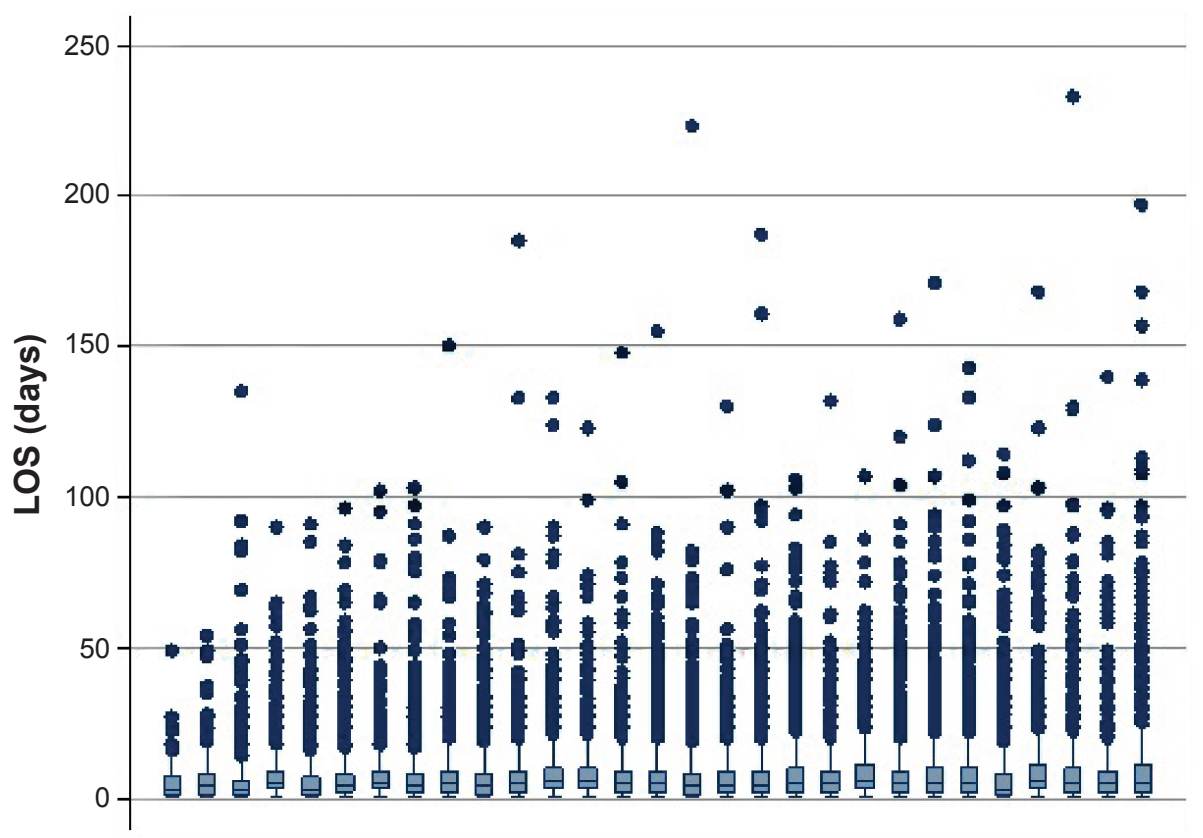

Figure 3 LOS (box and whisker plot of median, interquartile ranges, and outliers) of all COPD admissions (2006-2010) of patients registered with London general practices not having had a COPD admission in the 12 months prior to their first admission after April I, 2006 to English hospitals reporting at least I00 such admissions. Abbreviation: LOS, length of stay. 


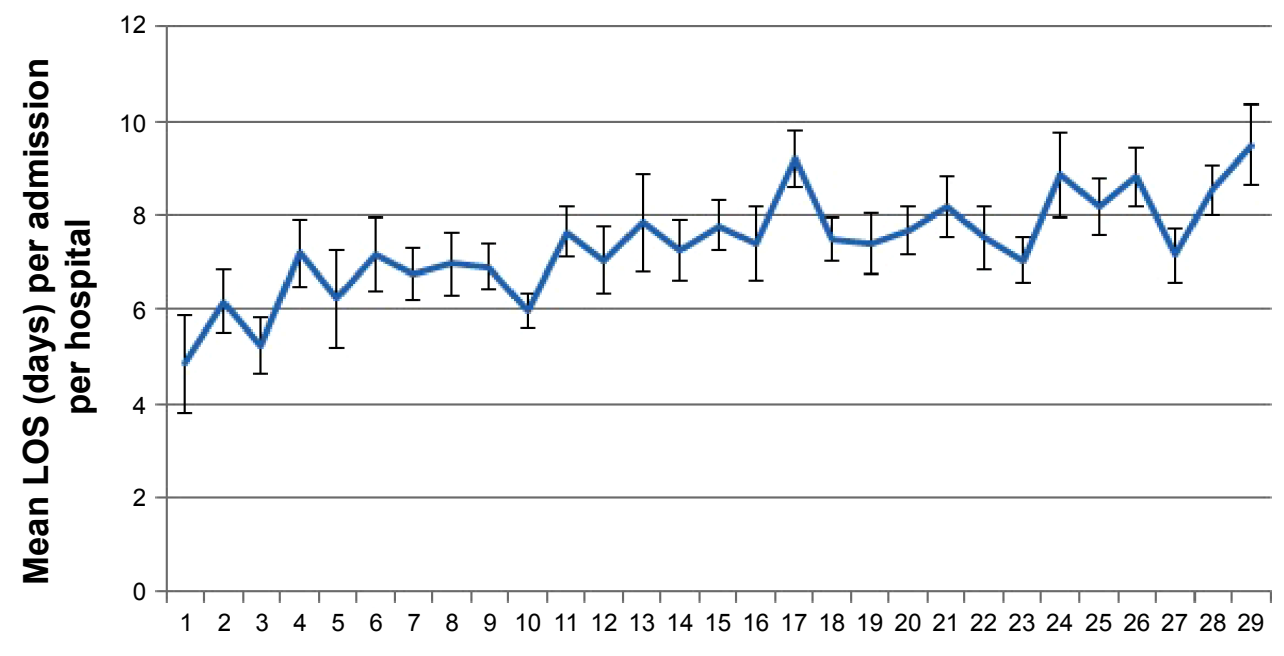

Hospital

Figure 4 Mean LOS $( \pm 95 \% \mathrm{Cl})$ of all COPD admissions $(36,893)$ to included English hospitals between 2006-20I0, and adjusted for clustering, age, sex, and geographical deprivation score of patients.

Abbreviations: $\mathrm{Cl}$, confidence interval; LOS, length of stay.

\section{Interpretation}

This was the first study to describe the LOS for first and subsequent admissions for COPD among patients not admitted within the previous year. There was a narrowing of the time interval between successive admissions that was sustained throughout the study. The time to recovery within hospital from a COPD exacerbation was not related to the number of previous admissions of a patient. Suissa et al have demonstrated that the severity of COPD worsens with successive admissions. ${ }^{7}$ In this study, the critical nature of the illness at the time of admission did not lead to longer treatment. This argues against the role of severity in predicting LOS.
Differences between hospitals in their mean LOS were relatively consistent irrespective of the inclusion of long-stay patients. The variation in patients admitted for $\leq 10$ days, which accounted for the majority of admissions, was barely affected by death. In the absence of evidence for the role of age, severity, or socioeconomic deprivation in determining LOS, hospital activity appears to be the major determinant of LOS. This is consistent with the results from a recent Spanish study in which the hospital was the best predictor of LOS. ${ }^{34}$ It is likely that the variation in LOS between hospitals can be accounted for by variation in the configuration of hospital respiratory units and variation in the care provided to COPD

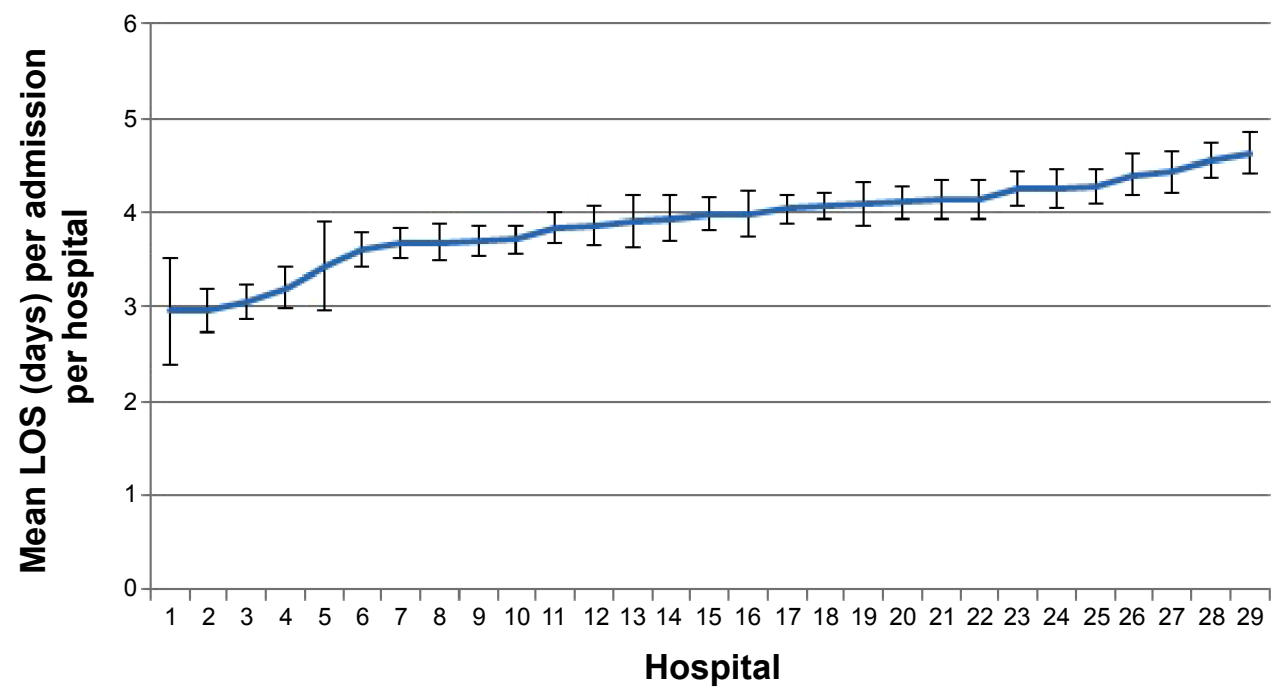

Figure 5 Mean LOS $( \pm 95 \% \mathrm{Cl})$ of COPD admissions $\leq 10$ days $(29,255)$ to included English hospitals between 2006-2010, shown in ascending order and adjusted for clustering, age, sex, and geographical deprivation score of patients.

Abbreviations: $\mathrm{Cl}$, confidence interval; LOS, length of stay. 


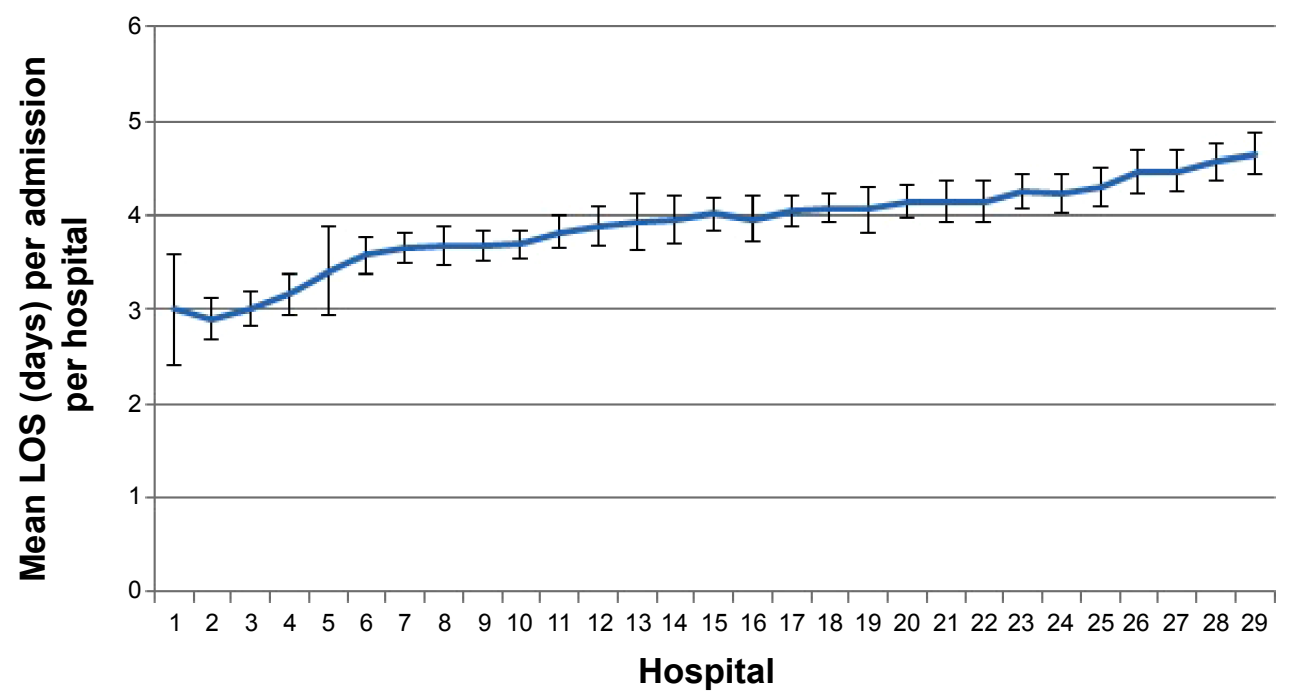

Figure 6 Mean LOS $( \pm 95 \% \mathrm{Cl})$ of COPD admissions $\leq 10$ days $(27,813)$ to included English hospitals between 2006-20I0, and adjusted for clustering, age, sex, and geographical deprivation score of patients.

Note: Deaths excluded.

Abbreviations: $\mathrm{Cl}$, confidence interval; LOS, length of stay.

patients. ${ }^{20}$ This may include differences in the provision of supported discharge programs, which has been associated with reductions in LOS..$^{22}$ Other possible causes include variation in the efficiency of hospitals in discharging patients, the provision of community social care to allow safe discharge, ${ }^{16}$ and differing hospital policies that determine the intensity of treatment provided to patients. By amalgamating constituent hospitals into their larger NHS trusts and including only hospital trusts that met the threshold for admissions, this study was able to compare units of equivalent size and with similar numbers of COPD admissions.

Much has been said about the effect of the difference in inhospital activity at weekends compared to weekdays. ${ }^{35-38}$ Raising the numbers of COPD admissions discharged at the weekend may provide an opportunity to reduce LOS and costs overall with respect to COPD admissions. There may be risks to patients due to being discharged at times when community services are working with fewer staff.

\section{Strengths of the study}

Data were comprehensive as they included all NHS COPD admissions of patients registered at London general practices to English hospitals. The patient inclusion criteria were selected to remove the bias that might have resulted from a recent previous admission, which is considered to be a significant factor in worsening disease, ${ }^{7}$ and possibly in prolonging the LOS of subsequent admissions. As it turned out, this was not a factor in LOS. The presence of multiple admissions with a LOS of 0 days would have caused a negative skew effect on the mean LOS results. This was avoided by recoding same-day admission and discharges as having a LOS of 0.5 days. By comparing hospitals with respect to COPD admissions of $\leq 10$ days, the disproportionate impact that longer admissions have on the mean LOS of each hospital was removed. This provided a better reflection of the hospital's overall management of COPD admissions.

\section{Limitations of the study}

Data were not available on some patient characteristics, among them the severity of COPD, and patient performance status and comorbidities, which may have been predictors of LOS. ${ }^{11-13} \mathrm{We}$ have discussed the role of severity earlier. Controlling for age and socioeconomic deprivation has provided a proxy for comorbidity, since comorbidity increases with age ${ }^{12}$ and socioeconomic deprivation. ${ }^{39}$

Little information was known about individual hospitals or the variation between them in the process or type of care given to COPD patients. No data were available on staffing numbers or the use of supported discharge schemes and guidelines, both predictors of LOS. ${ }^{19}$ Although the results suggest that differences in type of care provided by hospitals were responsible for some of the variation in LOS between hospitals, this study could not comment on what these differences were. A limitation of merging hospitals is that it assumes that management practice was equivalent across each merged hospital within a single trust. There may have been significant differences in practice between these hospitals, accounting for variation between them in LOS of COPD patients, which would be 
underestimated by the merging of hospital trusts. Concerns remain regarding the accuracy of routinely collected data sources, including HES admissions data. At the time of this analysis, the accuracy of HES data had been audited and the frequency of clinical coding errors was estimated at $11 \%{ }^{40}$

\section{Conclusion}

This study has provided new insights into the distribution of LOS among patients admitted to NHS hospitals with COPD exacerbations. These findings should be of interest to those commissioning services from these hospitals. The LOS per COPD admission reduced significantly over the study period. Successive admissions of COPD patients did not lead to an increased LOS per admission, suggesting that COPD severity does not influence LOS. The lack of variation in LOS from frequent admissions does not support subjecting those patients who are admitted frequently to more intensive treatment in order to reduce their LOS. The significant variation in LOS found between hospitals was not explained by patient age, sex, or socioeconomic deprivation, and is more likely to represent the effect of hospital or community factors. The findings suggest that unnecessary long LOS might be avoided by reconfiguration in the delivery of COPD services within hospitals and the community. We recommend a retrospective analysis of COPD admissions to individual hospitals, stratified by LOS, which would investigate patient demographics and the therapeutic characteristics of each admission.

\section{Acknowledgments}

Funding: Guy's and St Thomas' Charity (reference no: G060703). This research was supported by the National Institute for Health Research (NIHR) Biomedical Research Centre at Guy's and St Thomas' NHS Foundation Trust and King's College London. The views expressed are those of the authors and not necessarily those of the NHS, the NIHR, or the Department of Health. Dr Harries was supported by an NIHR in-practice fellowship.

\section{Author contributions}

THH and PW devised the study and all authors contributed to its design. PW and HT contributed to data collection. THH, PW, SC, PS, and AG contributed to data analysis. THH and PW wrote the first draft. All authors commented and contributed to the final paper. PW is guarantor for the paper.

\section{Disclosure}

The authors report no conflicts of interest in this work.

\section{References}

1. Mathers CD, Loncar D. Projections of global mortality and burden of disease from 2002 to 2030. PLoS Med. 2006;3(11):e442.

2. National Clinical Guideline Centre (UK). Chronic Obstructive Pulmonary Disease: Management of Chronic Obstructive Pulmonary Disease in Adults in Primary and Secondary Care. London, UK: Royal College of Physicians; 2010. Available from: http://www.ncbi.nlm.nih. gov/books/NBK65043/. Accessed September 17, 2014.

3. Britton M. The burden of COPD in the U.K.: results from the Confronting COPD survey. Respir Med. 2003;97 Suppl C:S71-S79.

4. Halpin DM, Miravitlles M. Chronic obstructive pulmonary disease: the disease and its burden to society. Proc Am Thorac Soc. 2006;3(7): 619-623.

5. Donaldson GC, Seemungal TA, Bhowmik A, Wedzicha JA. Relationship between exacerbation frequency and lung function decline in chronic obstructive pulmonary disease. Thorax. 2002;57(10):847-852.

6. Niewoehner DE. The impact of severe exacerbations on quality of life and the clinical course of chronic obstructive pulmonary disease. Am J Med. 2006;119(10 Suppl 1):38-45.

7. Suissa S, Dell'Aniello S, Ernst P. Long-term natural history of chronic obstructive pulmonary disease: severe exacerbations and mortality. Thorax. 2012;67(11):957-963.

8. Soler-Cataluña JJ, Martínez-García MÁ, Román Sánchez P, Salcedo E, Navarro M, Ochando R. Severe acute exacerbations and mortality in patients with chronic obstructive pulmonary disease. Thorax. 2005; 60(11):925-931.

9. Crockett AJ, Cranston JM, Moss JR, Alpers JH. An association between length of stay and co-morbidity in chronic airflow limitation. Int J Qual Health Care. 2000;12(1):41-46.

10. Department of Health (UK). Consultation on a Strategy for Services for Chronic Obstructive Pulmonary Disease (COPD) in England. London, UK: Department of Health; 2010. Available from: https://www.gov. uk/government/uploads/system/uploads/attachment_data/file/213840/ dh_113279.pdf. Accessed January 5, 2014.

11. Agboado G, Peters J, Donkin L. Factors influencing the length of hospital stay among patients resident in Blackpool admitted with COPD: a cross-sectional study. BMJ Open. 2012;2(5). pii: e000869.

12. Roberts CM, Stone RA, Lowe D, Pursey NA, Buckingham RJ. Co-morbidities and 90-day outcomes in hospitalized COPD exacerbations. COPD. 2011;8(5):354-361.

13. Tsimogianni AM, Papiris SA, Stathopoulos GT, Manali ED, Roussos C, Kotanidou A. Predictors of outcome after exacerbation of chronic obstructive pulmonary disease. J Gen Intern Med. 2009;24(9): 1043-1048.

14. Baker EH, Janaway CH, Philips BJ, et al. Hyperglycaemia is associated with poor outcomes in patients admitted to hospital with acute exacerbations of chronic obstructive pulmonary disease. Thorax. 2006;61(4):284-289.

15. Burt MG, Roberts GW, Aguilar-Loza NR, Quinn SJ, Frith PA, Stranks SN. Relationship between glycaemia and length of hospital stay during an acute exacerbation of chronic obstructive pulmonary disease. Intern Med J. 2013;43(6):721-724

16. Wong AW, Gan WQ, Burns J, Sin DD, van Eeden SF. Acute exacerbation of chronic obstructive pulmonary disease: influence of social factors in determining length of hospital stay and readmission rates. Can Respir J. 2008;15(7):361-364.

17. Wang Y, Stavem K, Dahl FA, Humerfelt S, Haugen T. Factors associated with a prolonged length of stay after acute exacerbation of chronic obstructive pulmonary disease (AECOPD). Int J Chron Obstruct Pulmon Dis. 2014;9:99-105.

18. George PM, Stone RA, Buckingham RJ, Pursey NA, Lowe D, Roberts CM. Changes in NHS organization of care and management of hospital admissions with COPD exacerbations between the national COPD audits of 2003 and 2008. QJM. 2011;104(10):859-866.

19. Price LC, Lowe D, Hosker HSR, Anstey K, Pearson MG, Roberts CM. UK National COPD Audit 2003: impact of hospital resources and organisation of care on patient outcome following admission for acute COPD exacerbation. Thorax. 2006;61(10):837-842. 
20. Connolly MJ, Lowe D, Anstey K, Hosker HS, Pearson MG, Roberts CM. Admissions to hospital with exacerbations of chronic obstructive pulmonary disease: effect of age related factors and service organisation. Thorax. 2006;61(10):843-848.

21. Hosker H, Anstey K, Lowe D, Pearson M, Roberts CM. Variability in the organisation and management of hospital care for COPD exacerbations in the UK. Respir Med. 2007;101(4):754-761.

22. Kastelik JA, Lowe D, Stone RA, Buckingham RJ, Roberts CM. National audit of supported discharge programmes for management of acute exacerbations of chronic obstructive pulmonary disease 2008. Thorax. 2012;67(4):371-373

23. Fitzpatrick J, Jacobson B. Mapping Inequalities across London. London Health Observatory at the King's Fund; 2001.

24. Hospital Episode Statistics [webpage on the Internet]. Leeds, UK: NHS Information Centre; 2014. Available from: http://www.hscic.gov.uk/ hes. Accessed January 5, 2014.

25. Holt PJ, Sinha S, Ozdemir BA, Karthikesalingam A, Poloniecki JD, Thompson MM. Variations and inter-relationship in outcome from emergency admissions in England: a retrospective analysis of Hospital Episode Statistics from 2005-2010. BMC Health Serv Res. 2014; $14: 270$.

26. Payne RA, Abel GA. UK indices of multiple deprivation - a way to make comparisons across constituent countries easier. Health Stat $Q$ Off Natl Stat. 2012;(53):22-37.

27. Purdy S, Griffin T, Salisbury C, Sharp D. Emergency respiratory admissions: influence of practice, population and hospital factors. $J$ Health Serv Res Policy. 2011;16(3):133-140.

28. Tashkin DP, Celli B, Senn S, et al. A 4-year trial of tiotropium in chronic obstructive pulmonary disease. N Engl J Med. 2008;359(15): 1543-1554.

29. Calverley PM, Anderson JA, Celli B, et al. Salmeterol and fluticasone propionate and survival in chronic obstructive pulmonary disease. N Engl J Med. 2007;356(8):775-789.

30. Calverley P, Pauwels R, Vestbo J, et al; TRial of Inhaled STeroids ANd long-acting beta2 agonists study group. Combined salmeterol and fluticasone in the treatment of chronic obstructive pulmonary disease: a randomised controlled trial. Lancet. 2003;361(9356): 449-456.
31. Wedzicha JA, Calverley PM, Seemungal TA, Hagan G, Ansari Z, Stockley RA; INSPIRE Investigators. The prevention of chronic obstructive pulmonary disease exacerbations by salmeterol/fluticasone propionate or tiotropium bromide. Am J Respir Crit Care Med. 2008; 177(1):19-26.

32. Vijayasaratha K, Stockley RA. Relationship between frequency, length, and treatment outcome of exacerbations to baseline lung function and lung density in alpha-1 antitrypsin-deficient COPD. Int J Chron Obstruct Pulmon Dis. 2012;7:789-796.

33. De Miguel-Díez J, Jiménez-García R, Hernández-Barrera V, et al. Trends in hospital admissions for acute exacerbation of COPD in Spain from 2006 to 2010. Respir Med. 2013;107(5):717-723.

34. Quintana JM, Unzurrunzaga A, Garcia-Gutierrez S, et al; IRYSSCOPD Group. Predictors of hospital length of stay in patients with exacerbations of COPD: a cohort study. J Gen Intern Med. Epub 2014 Dec 4.

35. National Health Service Commissioning Board. Everyone Counts: Planning for Patients 2013/14. Redditch, UK; National Health Service. Available from: http://www.england.nhs.uk/wp-content/ uploads/2012/12/everyonecounts-planning.pdf. Accessed January 5, 2014.

36. Aylin P, Yunus A, Bottle A, Majeed A, Bell D. Weekend mortality for emergency admissions. A large, multicentre study. Qual Saf Health Care. 2010;19(3):213-217.

37. Handel AE, Patel SV, Skingsley A, Bramley K, Sobieski R, Ramagopalan SV. Weekend admissions as an independent predictor of mortality: an analysis of Scottish hospital admissions. BMJ Open. 2012;2(6):pii. e001789.

38. Barba R, Zapatero A, Losa JE, et al. The impact of weekends on outcome for acute exacerbations of COPD. Eur Respir J. 2012;39(1):46-50.

39. Hawkins NM, Jhund PS, Simpson CR, et al. Primary care burden and treatment of patients with heart failure and chronic obstructive pulmonary disease in Scotland. Eur J Heart Fail. 2010;12(1):17-24.

40. Audit Commission. Improving Data Quality in the NHS: 2010. Annual Report on the PbR Assurance Programme. London, UK: Audit Commission; 2010. Available from: http://archive.audit-commission. gov.uk/auditcommission/sitecollectiondocuments/Downloads/260820 10pbrnhsdataqualityreport.pdf. Accessed January 5, 2014.
International Journal of COPD

\section{Publish your work in this journal}

The International Journal of COPD is an international, peer-reviewed journal of therapeutics and pharmacology focusing on concise rapid reporting of clinical studies and reviews in COPD. Special focus is given to the pathophysiological processes underlying the disease, intervention programs, patient focused education, and self management protocols.

\section{Dovepress}

This journal is indexed on PubMed Central, MedLine and CAS. The manuscript management system is completely online and includes a very quick and fair peer-review system, which is all easy to use. Visit http://www.dovepress.com/testimonials.php to read real quotes from published authors. 